\title{
城市文化氛围满意度及影响因素
}

\author{
谌 ${ }^{\text {网 }}{ }^{1}$, 党云晓 ${ }^{2^{*}}$, 张文忠 ${ }^{3}$, 马仁锋 ${ }^{4}$ \\ (1. 北京联合大学应用文理学院, 北京 $100191 ; 2$. 浙江财经大学土地与城乡发展研究院, 杭州 310018 ; \\ 3. 中国科学院可持续发展分析与模拟重点实验室, 中国科学院地理科学与资源研究所, 北京 100101; \\ 4. 宁波大学地理与空间信息技术系,浙江 宁波 315211)
}

\begin{abstract}
摘 要: 城市文化氛围是影响居民生活质量和城市宜居性的重要要素。本文基于对全国 40 个重点城市近万份常住 居民的城市文化氛围满意度调查数据, 采用多层线性模型定量识别影响城市文化氛围满意度的主要因素。结果显 示: 在城市层级纳人考察的指标中, 文化消费层次、文化设施及历史文化积淀对城市文化氛围满意度均有显著正向 的影响; 个体属性层级中, 居民家庭月收人、年龄和职业对城市文化氛围满意度的影响显著, 高收人、中等年龄段群 体对城市文化氛围的满意度较高, 农林牧渔水利生产人员的满意度较低。城市层级和个体层级的交互项结果显 示,在人均 GDP 越高和剧场、影剧院数越多的城市, 文化消费层次的多样性越高, 高收人阶层对城市文化氛围越满 意; 与此相反, 低收人阶层在人均 GDP 相对较低的城市满意度更高。
\end{abstract}

关 键 词: 城市文化氛围; 满意度; 影响因素; 多层线性模型

1 引言

良好的城市文化氛围能促进市民的身心健康 发展, 从而提高市民的城市居住获得感, 与居民生 活质量息息相关, 也是宜居城市建设的重要一环 (张文忠, 2007)。21世纪以来, 国际前沿研究表明, 多元文化是高素质人才最为关注的宜居要素之 一。如 Clark(2004)发现, 大学毕业的年轻人偏好具 有丰富多样文化娱乐方式的居住环境; Glaeser等 (2006)也指出, 多样化的文化娱乐设施和消费环境 等所代表的高质量生活能够使精英人群在城市集 中。许多学者还指出, 反映社会文化包容性的因素 能够解释高新技术就业的增长(Black et al, 2002; Glaeser, 2005; 蔡建明, 2016)。由于高技术产业布 局往往与高学历、高科技人才密切相关, 即文化可 以通过影响人才的定居决策间接影响企业的空间 选址(Florida, 2002), 人才和高技术企业的集聚将提 高城市创新能力, 最终推动城市可持续发展。
目前中国对城市居住环境、宜居城市等的研究 主要关注服务设施、交通出行等领域,对文化氛围 的研究相对较少。近年来, 随着中国经济社会的快 速发展及全球化的深人, 城市发展已经迈人新阶 段,发展目标和重点逐渐由重视物质与实体空间的 规划和建设向城市文化和精神塑造转变(张文忠, 2016)。随之, 如何塑造城市文化特色，打造城市文 化品位成为城市文化研究的核心议题。许多研究 探讨如何将文化与产业相结合, 通过文化产业的发 展实现城市功能转型(马仁锋, 2012)、推动城市更新 (谌丽等, 2010), 甚至将文化产业视为提升城市竞争 力的引擎(钟雅琴, 2011); 强调将文化落实于城市空 间设计之中(何序君等, 2012), 探讨文化建设诉求下 的地理环境改造、建筑风格等方面的城市空间塑造 (盛明洁, 2014)。还有许多研究从城市文化设施角 度出发, 探讨文化设施的数量、规模和种类对城市 文化建设的影响(王京山等, 2005; 邓乙桂, 2009; 黄 鹤等, 2012), 以及关注文化设施的空间布局如何影

收稿日期:2017-06;修订日期:2017-08。

基金项目 : 国家自然科学基金项目(41230632,41601160); 北京市自然科学基金项目(9164027) [Foundation: National Natural Science Foundation of China, No. 41230632, No. 41601160; Beijing Natural Science Foundation, No.9164027]。

作者简介: 谌丽(1985-),女,四川绵阳人, 讲师, 主要从事城市居住环境研究,E-mail: chenlicas@foxmail.com。

通讯作者:党云晓(1987-),女,河南济源人,讲师,主要从事城市问题与区域发展研究,E-mail: dangyx@zufe.edu.cn。

引用格式: 谌丽, 党云晓, 张文忠, 等. 2017. 城市文化氛围满意度及影响因素[J]. 地理科学进展, 36(9): 1119-1127. [Chen L, Dang Y X, Zhang W Z, et al. 2017. Satisfaction on urban cultural environment and influencing factors[J]. Progress in Geography, 36(9): 1119- 1127.]. DOI: $10.18306 /$ dlkxjz.2017.09.008 
响其功能发挥(张景秋, 2004; 吕斌等, 2012)。但这 些研究很少直接以居民诉求为切人点。

在城市文化主观感知研究方面, 现有文献主要 是从地方感、认同等视角讨论 “他者” 城市文化意 象。例如张虹菲等(2007)分析了国外背包客在北京 旅游的动机和满意度; 白凯(2012)探讨了旅华美国 游客的旅游目的地城市色彩意象认知的发生机制 与过程模型; 蔡晓梅等(2012)分析了广州高星级酒 店外籍管理者对广州的地方景观感知的形成机制; 曹永荣等(2012)分析了国际人士眼中上海总体印象 满意度; 尹小娜等(2015)运用网络文本分析法解读 了游客对福州三坊七巷的文化感知。讨论本地居 民如何看待城市文化、是否认可城市文化氛围的研 究尚较少, 仅有少量探讨了本地市民对城市文化设 施的满意度(陈永国等, 2012)。此外, 受数据可获性 影响, 已有研究均以单个城市或旅游目的地为对象, 分析居民或游客的文化感知; 受限于城市之间大规 模的文化氛围满意度调查数据, 未能对城市文化氛 围满意度的差异及其形成影响因素进行深人研究。

城市文化氛围的主观感知研究对于城市文化 建设和国际竞争力提升具有重要意义。尤其是本 地居民对城市文化氛围的感知直接关系宜居的获 得感, 由此引发的居住选择和城市创新创业的链式 效应是知识经济时代影响城市发展的重要动因。 本文以宜居城市建设中的文化氛围为切人点, 基于 既有文献, 以全国 40 个重点城市近万份宜居城市调 查问卷数据为基础, 分析居民对城市文化氛围的满 意度评价差异,并采用多层线性模型定量考察面向 居民的城市文化生活指标对满意度评价的影响。 本文将丰富城市文化和宜居城市研究的领域、定量 模拟方法,可为城市文化建设提供依据。

\section{2 研究设计}

\section{1 分析框架}

满意度是衡量消费者获取的客观福利与其期 望水平之间差异的指标, 常被用于测度居住环境对 居民需求的满足程度(Campbell et al, 1976)。本文 的文化氛围是宜居城市框架下的一个要素, 其满意 度表征居民体验的文化环境与其文化需求之间的 差异。相应地, 其影响因素包括供给和需求两方面 (图 1)。已有文献(王益澄, 2003; 李开宇等, 2005)表 明, 影响城市文化供给的因素包括历史积淀、文化 投人、文化产业、文化设施、文化交流、文化科技、文 化消费等诸多方面。其中, 直接影响城市文化氛围

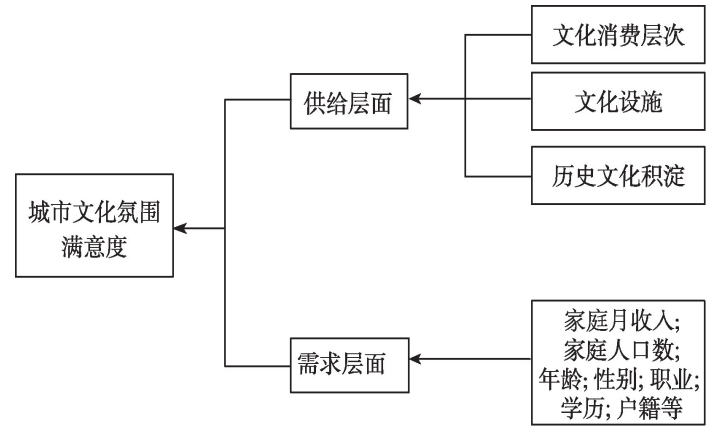

图 1 城市文化氛围满意度的影响因素

Fig. 1 Influencing factors of satisfaction level on urban culture environment

的包括文化消费层次、文化设施及历史文化积淀 等。文化消费层次是指城市能够提供的文化消费 的种类和数量, 文化消费层次越丰富,越有利于形 成丰富多元的城市生活方式,有利于提升居民的城 市文化氛围满意度; 文化设施是居民文化体验、消 费的场所, 直接影响城市文化氛围满意度评价; 历 史文化积淀是城市居民的记忆传承和精神家园, 厚 重的历史能提升宜居城市的内涵, 促进居民的城市 文化氛围满意度。此外, 文化需求和偏好与居民自 身属性(性别、年龄、学历、职业等)有关, 同时作为社 会人, 文化需求也受到家庭成员的影响。通常来 说, 个人的文化需求偏好往往与家庭而非个人的收 人有关。由于外地人可能存在文化隔阂,抑或某些 设施存在户籍门槛, 因此是否具有本地城市户口也 可能影响居民的城市文化氛围满意度。

本文将验证以上因素对城市文化氛围满意度 的影响是否成立, 并且关注城市文化供给如何影响 不同居民的主观感知。

\section{2 模型与变量设置}

鉴于本文模拟城市层级的文化生活供给因素 及个体层级的属性因素对城市文化氛围满意度的 影响, 数据结构同时涵盖了城市与个体 2 个层级。 考虑到数据的嵌套性, 使用多层线性模型(Multilevel Model)进行模拟, 其显著优点是模型估计系数及 其标准误充分考虑了不同层级人口结构的收玫性 (Ballas et al, 2012), 模型能将不同地理层级要素对 个体城市文化氛围满意度的影响加以区分, 并精确 计算出每个地理层级要素对解释城市文化氛围满 意度差异的贡献。由于调查问卷对城市文化氛围 满意度的测度结果为有序分类的李克特量表式变 量, 按照采集的满意度(非常不满意、不满意、一般、 满意、非常满意), 分别将其转换为百分制得分, 对 应分值为 $100 、 80 、 60 、 40 、 20$ 。本文文采用的多层线 
性模型如下:

$$
\begin{gathered}
y_{i j}=a_{0}+\sum_{m=1}^{M}\left(\beta_{m} x_{m i j}\right)+\sum_{n=1}^{N}\left(\delta_{n} w_{n j}\right)+u_{j}+\varepsilon_{i j} \\
u_{j} \sim N\left(0, \sigma_{u}^{2}\right), \varepsilon_{i j} \sim N\left(0, \sigma_{e}^{2}\right), \operatorname{cov}\left(u_{j}, \varepsilon_{i j}\right)=0
\end{gathered}
$$

式中: $i 、 j$ 分别表示个体和城市层级; $y_{i j}$ 表示居民对 城市文化氛围的满意度得分; $\boldsymbol{x}_{m i j}$ 和 $\boldsymbol{w}_{n j}$ 分别对应 个体和城市层级的解释变量矩阵; $a_{0}$ 表示截距项; $\beta_{m} 、 \delta_{n}$ 分别表示个体和城市层级第 $m$ 个和第 $n$ 个 解释变量的回归系数; $u_{j}$ 和 $\varepsilon_{i j}$ 分别表示个体和城 市层级的残差; $u_{j}$ 服从均值为 0 、方差为 $\sigma_{u}{ }^{2}$ 的正态 分布, $\varepsilon_{i j}$ 服从均值为 0 、方差为 $\sigma_{e}{ }^{2}$ 的正态分布; $u_{j}$ 和 $\varepsilon_{i j}$ 被假定为相互独立。 $\sigma_{u}{ }^{2}$ 和 $\sigma_{e}{ }^{2}$ 分别表示因变量文化 氛围满意度在城市和个体两个层级的变异程度(方 差)。根据模型(2), 个体之间的城市文化氛围满意 度的方差为 $\operatorname{var}\left(y_{i j}\right)=\sigma_{u}{ }^{2}+\sigma_{e}{ }^{2}$; 同一城市不同个体城市 文化氛围满意度间的协方差为: $\operatorname{cov}\left(y_{i j}, y_{i j}\right)=\operatorname{cov}\left(u_{j}+\right.$ $\left.\varepsilon_{i j}, u_{j}+\varepsilon_{i j}\right)=\sigma_{u}^{2}$ 。因此, 同一城市内个体间的相互联系 程度为: $\rho=\sigma_{u}{ }^{2} /\left(\sigma_{u}{ }^{2}+\sigma_{e}{ }^{2}\right)$ 。在多层模型文献中, $\rho$ 通常 被称为组内相关系数或者方差分解系数, 用于衡量 组间差异对因变量的解释能力(Goldstein, 2003)。

关于模型估计方法, 可采用迭代广义最小二乘 方法(Iterative Genelised Least Squares, IGLS ), 或者 基于马尔科夫链蒙特卡洛模拟的贝叶斯估计方法 (Bayesian Monte Carlo Markov Chain, MCMC) (Goldstein, 2003)。考虑到模型结构设置的复杂性, 为达到更加准确并且稳健的估计结果 (Browne et

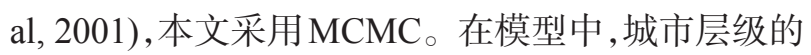
自变量包括表征历史文化积淀的文物保护单位, 表 征文化设施的百人公共图书馆藏书, 剧场、影剧院 数和博物馆数, 以及表征文化消费水平的人均 GDP。因为研究指出当人均 GDP 发展到一定阶段, 人们的消费将向追求精神文化转变, 产业结构也将 出现向文化产业的转向(李海舰等, 2010)等。个体 层级的自变量包括家庭月收人、家庭人口数和个人 年龄、性别、学历、职业、户籍等。

\section{3 数据来源}

采用的主观数据来自中国科学院地理科学与 资源研究所宜居城市课题组于 2015 年开展的直辖 市、省会城市、计划单列市等 40 个重点城市问卷调 查数据。调查对象为居住在该城市半年以上的常 住人口。该调查中, 城市文化氛围和服务设施可达 性、交通便捷性、环境健康性、安全性等共同作为宜 居城市的重要组成要素, 居民对其满意度的评价构
成问卷主体部分, 此外还包括被调查者的自然与社 会经济属性状况。问卷量为 12000 份, 回收 9325 份 有效问卷,有效率为 $77.7 \%$ 。客观数据来自于《中国 城市统计年鉴 2015》以及国家文物局官方网站等。 问卷数据与统计数据的统计性分析见表 1 。

\section{3 结果与分析}

\section{1 不同城市的文化氛围满意度比较}

在被调查的 40 个城市中, 居民对城市文化氛围 最为满意的城市依次为济南、上海、北京、深圳和天 津, 得分分别为 $66.35 、 65.83 、 65.76 、 65.36$ (图2)。其 中, 济南和北京均为历史文化名城, 济南有遐迩闻 名的龙山文化、名士文化、泉文化，北京是全国的文 化中心, 两座城市历史文化积淀深厚, 居民对城市 文化氛围的满意度较高。上海、天津是近代形成的 开埠通商城市, 异国文化和本土文化交融, 因此也 形成了令居民满意的城市文化氛围。排名靠前的 城市中, 出人意料的是建城史较短的深圳。通过整 理深圳的文化政策,不难发现深圳的文化建设力度 极大, 例如在城市规划与实施中重视历史文化遗存 的保护与开发力度, 对大鹏古城、南头古城、宋少帝 陵及各种民间文化信仰场所进行整体包装,提升了 城市历史文化内涵; 同时还积极利用“深圳国际高 新技术博览会、文化产业博览会”和创意产业政策 推动现代文化名城建设; 作为年轻人口比重较高的 城市, 深圳非常关注休闲旅游文化市场, 发展诸如 美术馆、音乐厅、24 小时书店/书吧等高品位文化休 闲场所,增强城市的文化亲和力; 并在全国率先引 进北京大学、哈尔滨工业大学、中国科学院、香港大 学等院所的高教优势与科研优势推动本土人才培 养、科研创新等等。此外, 深圳文化发展速度大大 超出了本地居民的预期,也是其城市文化氛围满意 度评价得分较高的原因。

城市文化氛围满意度最低的城市包括三亚、哈 尔滨、南昌、拉萨和郑州等, 得分分别为 55.92 、 $57.18 、 57.99 、 58.17$ 和 58.60(图 2)。这些城市中, 尽 管三亚是独特的国际海岛旅游城市,拉萨具有鲜明 的藏地风情, 对于 “他者”而言文化特色鲜明, 但是 对于本地居民来说, 可供体验、参与的文化设施非 常少, 因此评分较低。同时发现,尽管西安历史文 化底蕴深厚, 也有许多重点大学分布, 但图书馆、影 剧院等文化设施数量不足, 城市文化氛围满意度评 价得分也不高。 
表 1 样本基本情况与变量描述性统计分析

Tab. 1 Variables in the model and statistical description of the samples

\begin{tabular}{|c|c|}
\hline 变量 & 变量描述(均值/百分比) \\
\hline \multicolumn{2}{|l|}{ 因变量 } \\
\hline 城市文化氛围满意度评价 & 61.6 分 \\
\hline \multicolumn{2}{|l|}{ 城市层级变量 } \\
\hline 人均GDP & 92238.7元 \\
\hline 剧场、影剧院数 & 33.7 个 \\
\hline 文物保护单位 & 278.3 处 \\
\hline 百人公共图书馆藏书 & 196.2 册 \\
\hline 博物馆数 & 29.2 个 \\
\hline \multicolumn{2}{|l|}{ 个体层级变量 } \\
\hline 家庭月收人 & $\begin{array}{l}<3000 \text { 元 }(12.2 \%) ; 3000 \sim 5000 \text { 元 }(19.6 \%) ; 5000 \sim 10000 \text { 元 }(29.0 \%) ; 10000 \sim 15000 \text { 元 }(25.6 \%) ; 15000 \sim \\
20000 \text { 元 }(6.6 \%) ; 20000 \sim 30000 \text { 元 }(5.2 \%) ;>30000 \text { 元(1.8\%) }\end{array}$ \\
\hline 家庭人口数 & 3.1 人 \\
\hline 年龄 & $<20$ 岁(10.7\%); 20 29岁(18.6\%); 30 39岁(27.1\%); 40 49岁(19.9\%); 50 59(12.3\%)岁;>60岁(11.4\%) \\
\hline 性别 & 男(51.7\%);女(48.3\%) \\
\hline 学历 & 初中及初中以下(11.2\%);高中(18.4\%);大学(56.2\%);研究生及以上(14.2\%) \\
\hline 职业 & $\begin{array}{l}\text { 国家机关党群组织企事业单位负责人 }(13.3 \%) \text {; 办事及有关人员 }(15.6 \%) \text {; 专业技术人员 }(20.8 \%) \text {; 生产 } \\
\text { 运输设备操作人员及有关人员 }(14.0 \%) \text {; 商业服务业人员 }(16.6 \%) \text {; 农林牧渔水利生产人员 }(12.2 \%) \text {; 其 } \\
\text { 他从业人员 }(7.5 \%)\end{array}$ \\
\hline 户籍 & 本地(64.8\%);外地(35.2\%) \\
\hline
\end{tabular}

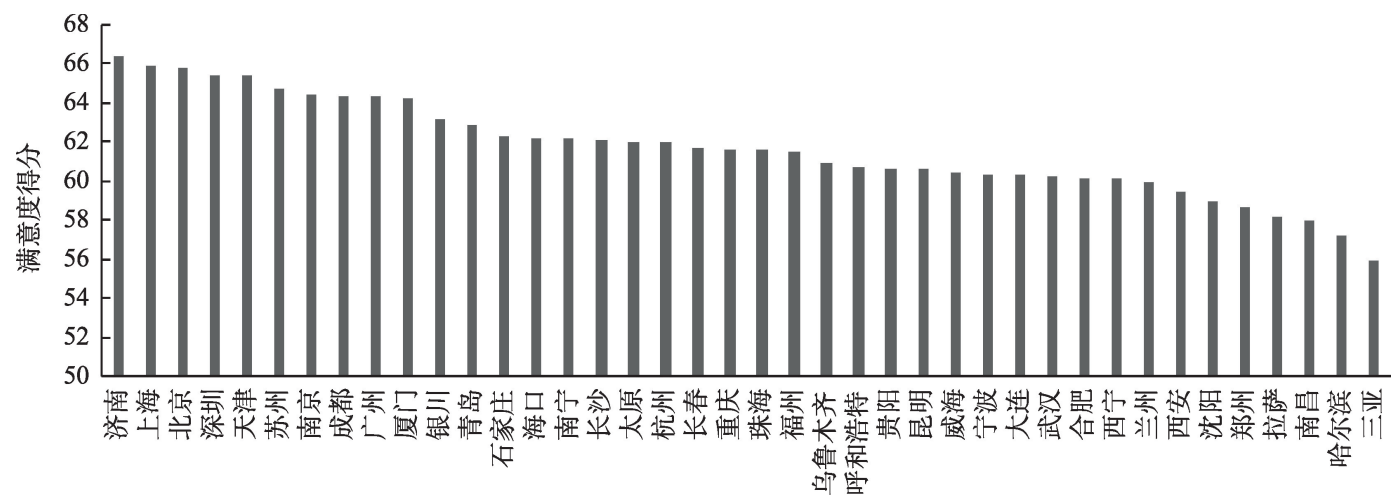

图 2 城市文化氛围满意度均值统计

Fig. 2 Residents' mean satisfaction level on urban cultural environment

\section{2 城市文化氛围满意度的模型估计与因素识别}

本文模型均采用 MLwiN(version 2.32)软件进 行估计, 基于 MCMC 估计的 MLwiN 详细操作见文 献(Browne, 2012)。对 MCMC 的设定为抽取 10000 个样本, 舍去前 5000 个样本, 最终的模型参数汇总 均基于之后的样本。采用偏差信息标准(Deviance Information Criterion, DIC)比较不同模型的拟合效 果。DIC 作为一个综合指标, 既考虑到不同模型对 数据的拟合程度, 又能考虑到模型的复杂程度。 DIC 值越小表明模型对数据的拟合程度越高, 一般 来说, 如果 DIC 值差别大于 5 则表明模型有明显的
优化(Browne, 2012)。

模型设定如下: 首先引人个体层级变量, 其次 引人城市层级变量。由于城市层级变量中, 人均 GDP, 剧场、影剧院数, 文物保护单位, 百人公共图 书馆藏书, 博物馆数之间存在显著的相关性, 为避 免共线性导致的模型估计结果不稳定, 将 4 个变量 分别引人模型。在引人变量之前, 首先建立不引人 任何解释变量的空模型, 计算个体与城市层级的方 差, 得到方差分解系数为 $0.46 \%$ 。方差分解系数可 衡量组间(城市层级)差异对因变量的解释能力。由 此可见,居民文化氛围满意度差异主要来自个体层 
级的异质性, 城市层级的异质性解释能力有限。模 型 II III IV、V 引人城市层级变量之后, DIC 有不同 程度减小, 说明引人城市层级变量对城市文化氛围 满意度的解释力更好。

根据模型 II III IV 、V 的估计结果(表 2), 城市 层级的人均 GDP, 剧场、影剧院数, 文物保护单位, 百人公共图书馆藏书, 博物馆数均对城市文化氛围 满意度有显著影响。其中, 人均 GDP 影响为正, 说 明城市经济发展水平更高时居民对城市文化氛围
感到更满意, 因为在经济发展水平更高的城市, 文 化产品和文化服务越丰富, 从而能够更好的满足居 民需求。文物保护单位对满意度的影响为正,说明 历史文化传承及底蕴浓厚的城市, 居民对城市文化 氛围更为满意, 因此城市在更新改造的进程中,应 注重对传统文化遗产的保护和修复,通过发扬传统 文化实现城市文化气质的提升,获取居民更高的认 可度。剧场、影剧院数, 百人公共图书馆藏书和博 物馆数对居民文化感受的影响同样为正,说明城市

\section{表 2 模型估计结果}

Tab. 2 Estimation results for the baseline model and models with additional city-scale variables

\begin{tabular}{|c|c|c|c|c|c|}
\hline & 模型 I & 模型 II & 模型 III & 模型 IV & 模型 V \\
\hline 常量 & $61.948^{* * *}(1.512)$ & $27.676^{* * *}(6.057)$ & $59.286^{* * * *}(1.925)$ & $53.206^{* * * *}(2.979)$ & $59.904^{* * * *}(1.815)$ \\
\hline \multicolumn{6}{|l|}{ 城市层级变量 } \\
\hline 人均 $\mathrm{GDP} /$ 元 & & $6.899^{* * * *}(1.256)$ & & & \\
\hline 剧场、影剧院数/个 & & & $1.72^{* * * *}(0.776)$ & & \\
\hline 文物保护单位/处 & & & & $1.353^{* *}(0.874)$ & \\
\hline 百人公共图书馆藏书/册 & & & & $2.375^{* * *}(0.828)$ & \\
\hline 博物馆数/个 & & & & & $1.564^{* *}(0.795)$ \\
\hline \multicolumn{6}{|l|}{ 个体层级变量 } \\
\hline \multicolumn{6}{|l|}{ 家庭月收人(参照组: <3000元) } \\
\hline $3000 \sim 5000$ & $1.721^{* *}(1.017)$ & $1.808^{*}(1.081)$ & $1.666^{* *}(0.981)$ & $1.779^{* *}(1.001)$ & $1.677^{* *}(0.997)$ \\
\hline $5000 \sim 10000$ & $0.934(0.985)$ & $0.944(1.015)$ & $0.871(0.919)$ & $0.930(0.947)$ & $0.842(0.962)$ \\
\hline $10000 \sim 15000$ & $0.899(1.014)$ & $0.886(1.002)$ & $0.766(0.930)$ & $0.850(0.992)$ & $0.739(1.006)$ \\
\hline $15000 \sim 20000$ & $3.096^{* *}(1.394)$ & $2.87^{* *}(1.375)$ & $2.821^{* *}(1.335)$ & $2.727^{* *}(1.386)$ & $2.767^{* *}(1.336)$ \\
\hline $20000 \sim 30000$ & $2.848^{* *}(1.527)$ & $2.624^{* *}(1.547)$ & $2.434^{* *}(1.43)$ & $2.547^{* *}(1.443)$ & $2.469^{* *}(1.422)$ \\
\hline$>30000$ & $3.160^{* * * *}(2.229)$ & $3.011^{*}(2.238)$ & $2.834^{*}(2.206)$ & $2.843(2.114)$ & $2.732(2.362)$ \\
\hline 家庭人口数 & $-0.215(0.261)$ & $-0.221(0.257)$ & $-0.177(0.241)$ & $-0.207(0.249)$ & $-0.213(0.242)$ \\
\hline 年龄 & $-0.265^{* * *}(0.202)$ & $-0.247(0.203)$ & $-0.222(0.196)$ & $-0.233(0.193)$ & $-0.239(0.192)$ \\
\hline 年龄平方 (1) & $-0.345^{* * *}(0.144)$ & $-0.338^{* *}(0.148)$ & $-0.33^{* * * *}(0.147)$ & $-0.318^{* *}(0.154)$ & $-0.329^{* *}(0.15)$ \\
\hline \multicolumn{6}{|l|}{ 性别(参照组:女性) } \\
\hline 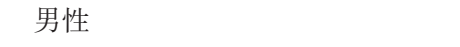 & $0.497(0.547)$ & $0.482(0.539)$ & $0.475(0.527)$ & $0.473(0.548)$ & $0.490(0.555)$ \\
\hline \multicolumn{6}{|l|}{ 学历(参照组:大学) } \\
\hline 初中及初中以下 & $-0.189(1.043)$ & $-0.027(1.066)$ & $-0.082(1.066)$ & $-0.061(1.086)$ & $-0.045(1.071)$ \\
\hline 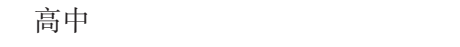 & $-0.448(0.790)$ & $-0.234(0.805)$ & $-0.272(0.819)$ & $-0.322(0.817)$ & $-0.335(0.794)$ \\
\hline 研究生及以上 & $-0.309(0.819)$ & $-0.208(0.861)$ & $-0.217(0.815)$ & $-0.229(0.803)$ & $-0.247(0.820)$ \\
\hline \multicolumn{6}{|c|}{ 职业(参照组: 国家机关党群组织企事业单位负责人) } \\
\hline 办事及有关人员 ～～～～～～ & $0.736(1.026)$ & $0.719(1.024)$ & $0.906(1.066)$ & $0.843(0.960)$ & $0.708(1.018)$ \\
\hline 专业技术人员 ～～～～～～～～～ & $2.020 * *(0.963)$ & $2.051 * *(0.970)$ & $2.109 * * *(0.971)$ & $2.136 * * *(0.929)$ & $1.969 * *(0.991)$ \\
\hline 生产运输设备操作人员及有关人员 & $0.052(1.073)$ & $0.125(1.057)$ & $0.223(1.074)$ & $0.264(1.058)$ & $0.025(1.072)$ \\
\hline 商业服务业人员 ～～～～～～～ & $0.869(1.033)$ & $0.898(1.027)$ & $1.062(1.052)$ & $1.036(0.995)$ & $0.893(1.013)$ \\
\hline 农林牧渔水利生产人员 & $-1.548^{* * * *}(1.093)$ & $-1.349(1.117)$ & $-1.293(1.147)$ & $-1.294(1.100)$ & $-1.421^{*}(1.114)$ \\
\hline 其他从业人员 ～～～～～～ & $0.562(1.386)$ & $0.526(1.409)$ & $0.593(1.412)$ & $0.757(1.327)$ & $0.485(1.313)$ \\
\hline \multicolumn{6}{|l|}{ 户籍(参照组:本地) } \\
\hline 外地 & $0.344(0.602)$ & $0.331(0.595)$ & $0.399(0.589)$ & $0.394(0.576)$ & $0.381(0.57)$ \\
\hline$D I C$ & 87435.258 & 87428.49 & 87428.69 & 87427.939 & 87429.81 \\
\hline$p D$ & 31.265 & 33.738 & 35.169 & 32.584 & 33.270 \\
\hline
\end{tabular}

注: (1)年龄平方为中心化处理的年龄平方,其值为(实际年龄-年龄均值) ${ }^{\wedge 2}$; 、*、*分别表示变量在 $90 \% 、 95 \% 、 99 \%$ 的置信水平上显著;城市层 级数值变量取对数。 
文化休闲场所的营造能够提升居民的城市文化氛 围满意度, 启示城市规划实践中, 应重视居民日益 增加的精神文化需求, 通过增加文化休闲场所, 改 善居民的文化生活品质。

在个体层级变量中, 家庭月收人对城市文化氛 围满意度有显著的影响, 家庭月收人在 15000 元及 以上居民的城市文化氛围满意度要显著高于家庭 月收人小于 3000 元的居民。这是由于, 一方面部分 城市文化产品存在价位门槛, 限制了低收人群体的 文化产品可获得性, 因此低收人群体的城市文化氛 围满意度更低; 另一方面, 与高收人群体相比, 低收 人群体受生计所迫, 更重视生活必须品以满足生活 需求, 对于高层次的文化追求相对较低, 城市的文 化建设对其影响较弱。为考察年龄是否存在非线 性的影响, 同时将年龄及中心化处理的年龄平方引 人模型。结果表明,年龄和年龄平方同时对文化氛 围满意度有显著影响, 其中年龄平方的影响为负, 说明居民的城市文化氛围满意度随着年龄增长先 升后降。中年人对城市文化氛围最满意, 其原因 是, 中年人的经济实力最强, 最有能力满足自身的 文化需求。此外, 城市针对老年人的城市文化设施 相对贫乏也是导致老年人对文化氛围满意度较低 的原因之一。与职业类别为国家机关党群组织企 事业单位负责人的群体相比, 从事农林牧渔水利生 产的就业群体对城市文化氛围感到更不满意, 是因 为后者收人水平相对较低, 支付文化产品与服务的 能力有限。

一般而言, 女性因为承担家庭劳动更多而不得 不牺牲消费娱乐时间, 并且城市建设中更多由男性 主导, 对女性的需求考虑不充分, 因此女性对城市 文化氛围满意度往往更低; 高学历人群的文化需求 和期望水平更高, 更难以得到满足; 外地户籍人群
在城市中存在文化隔阂,一些文化设施也存在户籍 门槛, 因此城市文化氛围满意度低于本地居民。本 文模型计算结果中的系数方向与这些经验一致,但 计算没有通过显著性检验, 表明性别、学历、户籍引 起的差异实际并不显著。

\section{3 城市文化氛围满意度跨层级影响因子分析}

图 3 显示了不同家庭月收人水平的居民文化氛 围满意度随城市人均 GDP 及剧场、影剧院数增长的 变化。从图 $3 \mathrm{a}$ 可以看出, 对于不同收人水平的居民 而言, 其城市文化氛围满意度随城市人均 GDP 的改 变而产生不同程度的变化。除家庭月收人为 3000 5000 元的居民其城市文化氛围满意度随人均 GDP 增加而降低以外, 其他收人水平的居民城市文化氛 围满意度均随人均 GDP 增加而提高; 其中, 家庭月 收人为 20000 30000 元的居民满意度提高速度最 快。剧场、影剧院数与家庭月收人的交互项也表现 出类似的特征(图 3b), 家庭月收人为 3000 元以下的 居民, 城市文化氛围满意度随剧场、影剧院数量增 加而降低, 对于其他收人水平的居民, 其满意度均 随剧场、影剧院数量增加而提高; 其中, 家庭月收人 为 30000 元以上的居民城市文化氛围满意度提高速 度最快。

由于人均 GDP 能表征城市文化消费的繁荣程 度, 而剧场、影剧院数则表征城市的文化娱乐活动, 因此,可从城市与个体层级交互项的分析结果得到 以下启示: 不同收人阶层的城市文化氛围满意度因 文化消费层次而异,城市经济发展水平越高, 城市 越繁荣, 文化消费层次越丰富, 高收人阶层越满意, 而经济发展相对滞后的小城市无法满足高收人阶 层的文化消费需求。这也符合 Clark(2004)、Glaeser 等(2006)和 Florida(2002)的研究结论: “越是精英阶 层, 越追求大城市的丰富多元的消费和娱乐方

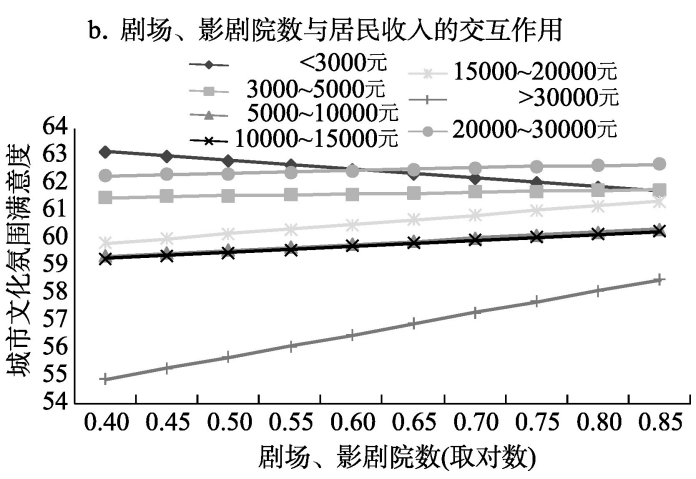

图 3 人均 GDP(a)/剧场、影剧院数(b)与居民收人的交互作用预测图

Fig. 3 Prediction of the interaction between per capita GDP / number of theaters and income 
式”。事实上, 早在 1983 年, Berry(1983)的《比较城 市化》书中指出: 多样化生活方式是大城市之所以 能源源不断吸引人口涌人的原因。低收人阶层在 经济发展水平稍微落后的城市满意度更高, 可能是 因为文化消费的价格更低; 而人均 GDP 较高城市, 由于缺乏面向低收人阶层的平民化文化产品, 低收 人阶层的满意度更低。

\section{4 结论与讨论}

\section{1 主要结论}

中国城市发展已经进人新动能阶段, 宜居城市 成为众多城市发展的目标, 其中面向居民的城市文 化和精神建设更是提到了前所未有的高度, 然而目 前地理学界尚缺乏对本地居民文化感知的研究。 本文结合全国 40 个重点城市的城市文化氛围满意 度调查数据, 首先分析居民对城市文化氛围满意度 评价的总体特征, 然后采用多层线性回归模型检验 城市文化生活指标及个体属性特征对城市文化氛 围满意度的影响, 为基于改善文化氛围而提高居民 生活质量、建设宜居城市提供了依据。

主要结论如下: (1)城市层级的变量对居民文化 氛围满意度呈现出正向的显著影响, 表明文化消费 层次、文化设施和历史文化积淀均能提升本地市民 的城市文化氛围满意度。(2)居民评价的差异更多 来自个体属性的不同。其中家庭月收人、年龄、职 业 3 个变量显著。总体来说, 家庭月收人越高, 对城 市文化氛围的满意度越高, 这可能与不同收人阶层 的文化消费层次和文化欣赏能力有关。年龄对文 化氛围满意度的影响表现为: 随着年龄的增加, 城 市文化氛围的满意度评价先增加再降低。职业类 型中, 农林牧渔水利生产人员的满意度较低。(3)不 同收人阶层的城市文化氛围满意度随文化消费水 平的改变而产生不同程度的变化, 总体上,城市人 均 GDP 提升, 剧场、影剧院等文化休闲场所增加, 对 高收人阶层的城市文化氛围满意度比低收人阶层 影响更大, 符合 Clark(2004)、Glaeser 等 (2006) 和 Florida(2002)的研究结论: 高收人精英阶层偏好丰 富多元的文化消费娱乐方式; 而低收人阶层的城市 文化氛围满意度下降或缓慢提高, 是由于人均 GDP 高的城市缺乏面向低收人阶层的平民化文化产品。

\section{2 讨论}

本文结论验证并补充了现有城市文化研究和 宜居城市研究的相关成果。文中采用本地居民对
“城市文化氛围”满意度作为评价的核心观察变量, 与通常采用的多而全的文化评价指标体系相比, 避 免了指标打分、取权重等加工部分, 能更加直接反 映居民对城市文化氛围的整体评价; 而纳人模型的 影响因素也围绕居民生活的方方面面展开。研究 结论表明, 文化消费层次、文化设施和历史文化积 淀及居民个体因素均对城市文化氛围满意度具有 显著影响。该结论是对以“他者”语境为主的文化 感知研究成果的重要补充。并且本文以大规模的 跨城市问卷数据为基础, 观测了城市文化氛围满意 度在不同城市的差异,并且从城市自身的特征寻找 这种差异存在的原因,扩展了城市文化感知文献的 研究尺度。同时研究结论对城市规划具有实践应 用价值, 对丰富居民文化生活、建设宜居城市具有 积极意义。

诚然, 本文也存在一些不足。后续研究希望能 纳人更加广泛的影响因子, 如文化交流、文化活动、 社区文化等,运用各种不同方法, 深人探讨居民对 城市文化氛围满意度的城市差异及影响机制。

\section{参考文献(References)}

白凯. 2012. 旅华美国游客目的地城市色彩意象认知研究

[J]. 地理学报, 67(4): 557-573. [Bai K. 2012. The research on American tourists about their cognition of color image of urban destination[J]. Acta Geographica Sinica, 67(4): 557-573.]

蔡建明, 林静. 2016. 中国新愿景下的文化与空间有机融合 的地理途径与机遇 [J]. 地理研究, 35(11): 2001-2014.

[Cai J M, Lin J. 2016. New marriage of culture and space under China's new vision: Approach and opportunities from geographical perspective[J]. Geographical Research, 35(11): 2001-2014.]

蔡晓梅, 朱泣. 2012. 高星级酒店外籍管理者对广州地方景 观的感知与跨文化认同 [J]. 地理学报, 67(8): 1057-1068. [Cai X M, Zhu H. 2012. Foreign managers' perception on urban landscape of place and their cross-cultural identity: A case study in Guangzhou[J]. Acta Geographica Sinica, 67 (8): 1057-1068.]

曹永荣, 韩瑞霞, 徐剑, 等. 2012. 基于因子分析的国际人士 眼中的上海城市印象满意度架构 $[\mathrm{J}]$. 上海交通大学学 报: 哲学社会科学版, 20(1): 51-57. [Cao Y R, Han R X, $\mathrm{Xu} \mathrm{J}$, et al. 2012. Satisfaction structure of the impression of Shanghai in the eyes of on international persons based on factor analysis[J]. Journal of ShangHai JiaoTong University: Philosophy and Social Sciences, 20(1): 51-57.] 谌丽, 张文忠. 2010. 历史街区地方文化的变迁与重塑: 以北 京什刹海为例 [J]. 地理科学进展, 29(6): 649-656. [Chen 
L, Zhang W Z. 2010. The change and reconstruction of local culture in response to urban renewal and globalization: A case study of Shichahai historic district[J]. Progress in Geography, 29(6): 649-656.]

陈永国, 丁东锋. 2012. 中国城市文化、体育休闲服务公众满 意度评价 [J]. 城市发展研究, 19(12): 129-133. [Chen Y G, Ding D F. 2012. Public satisfaction evaluation on culture and sports leisure in Chinese cities[J]. Urban Studies, 19 (12): 129-133.]

邓乙桂. 2009. 试论博物馆的文化休闲功能 [J]. 文史博览: 理 论, (7): 19-21. [Deng Y G. 2009. Museum of culture leisure [J]. Culture and History Vision: Theory, (7): 19-21.]

何序君, 陈沧杰. 2012. 城市规划视角下的城市文化建设研 究述评及展望 [J]. 规划师, 28(10): 96-100. [He X J, Chen C J. 2012. City culture development research review under urban planning[J]. Planners, 28(10): 96-100.]

黄鹤, 郑告. 2012. 国际视野下北京城市文化设施比较分析 [J]. 北京规划建设, (3): 80-83. [Huang H, Zheng H. 2012. Guoji shiyexia Beijing chengshi wenhua sheshi bijiao fenxi [J]. Beijing Planning Review, (3): 80-83.]

李海舰, 王松. 2010. 文化与经济的融合发展研究 [J]. 中国工 业经济, (9): 5-14, 25. [Li H J, Wang S. 2010. Research on integration development of culture and economy[J]. China Industrial Economics, (9): 5-14, 25.]

李开宇, 李九全, 魏清泉. 2005. 对城市社会文化要素经营的 探讨 [J]. 人文地理, 20(4): 102-105. [Li K Y, Li J Q, Wei Q Q. 2005. On social-cultural factors in urban management [J]. Human Geography, 20(4): 102-105.]

吕斌, 张玮璐, 王璐, 等. 2012. 城市公共文化设施集中建设 的空间绩效分析: 以广州、天津、太原为例 [J]. 建筑学报, (7): 1-7. [Lv B, Zhang W L, Wang L, et al. 2012. Preliminary analysis of the spatial performance of concentrated construction of urban public culture facilities: Case study of Guangzhou, Tianjin and Taiyuan[J]. Architectural Journal, (7): 1-7.]

马仁锋. 2012. 大都市创意空间识别研究: 基于上海市创意 企业分析视角 [J]. 地理科学进展, 31(8): 1013-1023. [Ma R F. 2012. The identification of creative spaces in Shanghai: Based on the space relation of creative enterprise[J]. Progress in Geography, 31(8): 1013-1023.]

盛明洁. 2014. 县辖市总体规划中的文化植人体系构建 [J]. 规划师, 30(11): 101-107. [Sheng M J. 2014. Cultural implantation in county level city master plan[J]. Planners, 30 (11): 101-107.]

王京山, 王锦贵. 2005. 论图书馆文化休闲功能的发挥[J]. 新 世纪图书馆, (5): 3-6. [Wang J S, Wang J G. 2005. On full play of leisure function of libraries[J]. New Century Library, (5): 3-6.]

王益澄. 2003. 城市文化现代化指标体系及其评价 [J]. 经济
地理, 23(2): 230-232. [Wang Y C. 2003. The city culture modernization indicator system and appraisal[J]. Economic Geography, 23(2): 230-232.]

尹小娜, 郑向敏. 2015. 基于网络文本分析的三坊七巷游客 文化感知研究 [J]. 北京第二外国语学院学报, 37(9): 6266, 33. [Yin X N, Zheng X M. 2015. A study of the tourists' cultural perception of the three lanes and seven alleys based on network text analysis[J]. Journal of Beijing International Studies University, 37(9): 62-66, 33.]

张虹菲, 吴佳, 李苗. 2007. 基于城市文化旅游资源的国外背 包客动机、行为与满意度研究: 以北京市为例 $[\mathrm{J}]$. 旅游学 刊, 22(10): 23-29. [Zhang H F, Wu J, Li M. 2007. International backpackers' motives, activities and satisfactions based on urban cultural tourism resources: A case study of Beijing[J]. Tourism Tribune, 22(10): 23-29.]

张景秋. 2004. 北京市文化设施空间分布与文化功能研究 [J]. 北京社会科学, (2): 53-60. [Zhang J Q. 2004. A study on spatial distribution of cultural facilities and cultural function in Beijing[J]. Social Science of Beijing, (2): 53-60.]

张文忠. 2007. 宜居城市的内涵及评价指标体系探讨 [J]. 城 市规划学刊, (3): 30-34. [Zhang W Z. 2007. Study on intrinsic meanings of the livable city and the evaluation system of livable city[J]. Urban Planning Forum, (3): 30-34.]

张文忠. 2016. 宜居城市建设的核心框架 [J]. 地理研究, 35

(2): 205-213. [Zhang W Z. 2016. The core framework of the livable city construction[J]. Geographical Research, 35 (2): 205-213.]

钟雅琴. 2011. 文化产业发展与城市意象再造 [J]. 暨南学报: 哲学社会科学版, 33(4): 110-116. [Zhong Y Q. 2011. The development of cultural industries and the reconstruction of the image of the city[J]. Journal of Jinan University: Philosophy and Social Sciences, 33(4): 110-116.]

Ballas D, Tranmer M. 2012. Happy people or happy places? A multilevel modeling approach to the analysis of happiness and well-being $[\mathrm{J}]$. International Regional Science Review, 35(1): 70-102.

Berry B J L. 1983. Comparative urbanization: Making of the Twentieth century[M]. New York: Palgrave Macmillan.

Black D, Gates G, Sanders S, et al. 2002. Why do gay men live in San Francisco[J]. Journal of Urban Economics, 51 (1): 54-76.

Browne W J. 2012. MCMC estimation in MLwiN: Version 2.26[M]. Bristol, UK: Centre for Multilevel Modelling University of Bristol.

Browne W J, Goldstein H, Rasbash J. 2001. Multiple membership multiple classification (MMMC) models[J]. Statistical Modelling, 1(2): 103-124.

Campbell A, Converse P E, Rodgers W L. 1976. The quality of American life: Perceptions, evaluations, and satisfactions 
[M]. New York: Russell Sage Foundation.

Clark T N. 2004. The city as an entertainment machine[J]. Research in Urban Sociology, 6(6): 357-378.

Florida R. 2002. The economic geography of talent[J]. Annals of the Association of American Geographers, 92(4): 743-755.

Glaeser E L. 2005. Review of Richard Florida's: The rise of the creative class[J]. Regional Science and Urban Economics, 35(5): 593-596.

Glaeser E L, Gottlieb J D. 2006. Urban resurgence and the consumer city[J]. Urban Studies, 43(8): 1275-1299.

Goldstein H. 2003. Multilevel statistical models[M]. 3rd ed. London, UK: Hodder Arnold.

\title{
Satisfaction on urban cultural environment and influencing factors
}

\author{
CHEN Li ${ }^{1}$, DANG Yunxiao ${ }^{2 *}$, ZHANG Wenzhong $^{3}$, MA Renfeng ${ }^{4}$ \\ (1. College of Applied Arts and Sciences, Beijing Union University, Beijing 100191, China; 2. College of Land and \\ Urban-rural Development, Zhejiang University of Finance and Economics, Hangzhou 310018, China; \\ 3. Institute of Geographic Sciences and Natural Resources Research, CAS, Beijing 100101, China; \\ 4. Department of Geography \& Spatial Information Technology, Ningbo University, Ningbo 315211, Zhejiang, China)
}

\begin{abstract}
Urban cultural environment plays an important role in promoting residents' quality of life and livability of cities. Favorable cultural atmosphere and rich cultural life will improve residents' health and wellbeing. Some scholars even argue that urban cultural environment is becoming one of the most valued elements for cultivating creativity and producing high-quality human resources. As a result, urban cultural environment catches attention of both urban geographers and policymakers. However, the increasing body of literature is mostly focused on urban culture from the perspective of "others", and few studies have discussed the issue from the perspective of "mine". Local residents' subjective perception is very important as it is an important factor that influences residential location choice and accordingly may affect a city's innovation capability. This research aimed to enrich the literature by studying the influencing factors of residents' satisfaction on urban cultural environment. The primary subjective data came from a large-scale survey conducted in 2015 in 40 typical cities of China, while the objective data came from statistic yearbooks. The study adopted a group of hierarchical multilevel models to examine the different influences from the city level and personal level. The survey results show that residents in Jinan, Shanghai, Tianjin, Shenzhen, and Beijing exhibit the highest satisfaction level among the 40 cities, while those who live in Sanya, Harbin, Nanchang, Lasa, and Zhengzhou are the least satisfied. The model results show that all the observed objective urban characteristics related with cultural environment, including cultural consumption, cultural facilities, as well as historical and cultural accumulation, show significant and positive effects on residents' satisfaction level. Some of the demographic characteristics of urban residents (monthly income, age, and occupation) exhibit significant impacts on their satisfaction. Residents with higher income are more satisfied with urban cultural environment than low-income people; residents at middle age are more satisfied than the younger and older groups; while people worked in agriculture, forestry, fishing, and water conservancy industry are less satisfied compared to those who work in government offices or companies. Analysis of interaction between urban hierarchy and personal hierarchy shows that high income residents are more satisfied with urban cultural environment in cities with higher per capita GDP and more theaters as there is higher cultural consumption diversity, whereas low-income residents are more satisfied when living in less prosperous cities. This finding is consistent with exiting studies, that is, so-called high-quality human resources prefer abundant and diversified cultural and entertainment consumption. This study may contribute to clarifying the relationship between individual subjective perception and urban characteristics. Also, the results may inform government policies guiding the development of highly livable cities
\end{abstract}

Key words: urban cultural environment; satisfaction; influencing factor; multilevel model 